\title{
Chemical Modifications for Intensity Variation and Spectrum Extension of Brazilein Extract from Sappanwood (Caesalpinia sappan L.)
}

\author{
Edia Rahayuningsih ${ }^{1, *}$, Wiratni Budhijanto ${ }^{1}$, Hana Fitria Prasasti ${ }^{2}$, and Meyta Tias Wahyuningrum ${ }^{2}$ \\ ${ }^{1}$ Bioresource Engineering Group, Chemical Engineering Department, Universitas Gadjah Mada, Jl. Grafika 2 Yogyakarta, Indonesia \\ ${ }^{2}$ Undergraduate Study Program, Chemical Engineering Department, Universitas Gadjah Mada, Jl. Grafika 2 Yogyakarta, Indonesia
}

\begin{abstract}
Aqueous extract of sappanwood (Caesalpinia sappan L.) was treated using acid-base and mordant additions in order to expand the intensity and spectra of the colors. The colorant molecule of sappanwood was brazilein, which gained its color characteristics through its double bonds. The results of this study confirmed three basic mechanisms which formed the fundamental for systematic optimization of natural dye applications. Acid addition induced protonation of the hydroxyl groups in the brazilein structure so that the electrons were distributed in the molecule more evenly. Therefore, the color intensity was reduced. Basic treatment created deprotonation of the hydroxyl groups and hence localized the electron on several spots. This made the color of the extract shifted to deeper tones. The addition of mordant created more significant change in color spectrum through the mechanism of chelation to form coordinated complexes. Transitional metals from group 1 and 2 did not chelate strongly so that the spectrum shift was not very obvious. However, transitional metals from group 3 had strong chelating character and consequently they could strongly bind the dye molecules to increase its intensity and shift the spectrum towards deeper colors.
\end{abstract}

\section{Introduction}

The plant of sappanwood or "kayu secang" in Bahasa Indonesia (Caesalpinia sappan L.) is considered a common plant in tropical region, including Indonesia. It is known as medicinal plant with various benefits. The claim of its pharmacological effect ranges from antiinflammatory up to cancer cell inhibitor [1]. The heartwood of this sappanwood (Fig. 1) is known as the source of brazilin (Fig. 2a) and brazilein (Fig. 2b) (the oxidated form of brazilin), which are both the active compounds in the wood to have the pharmaceutical benefits.

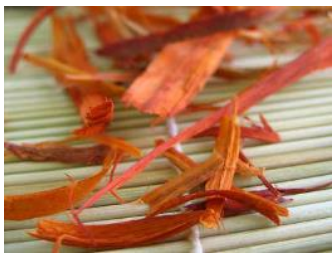

Fig. 1. Shaved heartwood of sappanwood

Brazilin is colorless, but brazilein bears natural color widely used in textile dyeing practices as watersoluble natural dye. This natural color had been detected in ancient fabrics to prove its attractiveness as textile dyes. Although it has been known and used for such a long time, its popularity still even increases into the modern era with wider uses as food colorant, $\mathrm{pH}$ indicator, and dye-sensitized solar cell [2].

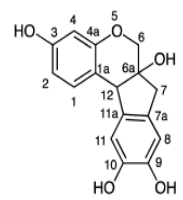

(a) Brazilin

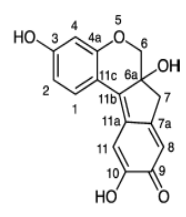

(b) Brazilein
Fig. 2. Structure of brazilin and brazilein as the active compounds in sappanwood extract [3]

Brazilein color spectra cover the range of yellowred depending upon the $\mathrm{pH}$ of the solution and the mordanting agents used in the dyeing process [3], [4]. Mordant is the chemicals added in the dyeing process to bind the chromophores into the textile fibers. Besides fixation function, mordants, which are the salts of transition metals, also play important role in changing the depth of the color and creating various shades of the same origin [5]. According to the classic Reichs-Aussch für Lieferbedingungen (RAL) system for color standardization, the possible colors obtainable from sappanwood extract are presented in Fig. 3. Both the spectrum and the intensity of the colors could be created from the same original extract of sappanwood by changing $\mathrm{pH}$ and addition of metal ions of the mordant salts [5], [6]. 


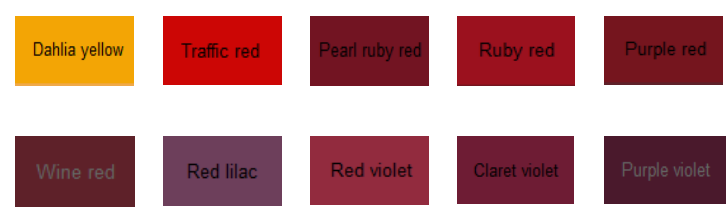

Fig. 3. Classic RAL System for color standard

Many studies have been published regarding the application of natural dyes for various uses [3], [6]. Other studies focused on the optimization of the extraction procedure, such as the rigorous methods to separate brazilin and brazilein [1], [2]. Still limited numbers of studies were focused on the color characteristics of the natural dyes. This paper presented a study on the effort to expand the intensity and spectra of the sappanwood extract. The study aimed to define the effect of $\mathrm{pH}$ and mordant salts in a systematic way so that the prospective users could decide which procedures to follow for their particular purposes.

\section{Research methodologies}

\subsection{Materials}

The raw material of sappanwood (Caesalpinia sappan L) was obtained from Beringharjo Market (Yogyakarta) in the form of dried thin shaved wood. Citric acid and acetic acid were used for acid modification while sodium hydroxide was chosen for the basic treatment. All chemicals were obtained from Merck at technical grades. Impurities of the chemicals were not disturbing the accuracy of the color formation because the solutions were quite diluted by water. For other variations of spectra, four chemicals were also tested, i.e. $\mathrm{Cu}$-Acetate $\left(\mathrm{Cu}\left(\mathrm{CH}_{3} \mathrm{COO}\right)_{2}\right), \mathrm{MgSO}_{4}, \mathrm{FeSO}_{4}$, and $\mathrm{Al}_{2}\left(\mathrm{SO}_{4}\right)_{3}$, which were all analytical grade from Sigma-Aldrich.

\subsection{Experimental set up}

The experiments were carried out in laboratory scale batch stirred reactor equipped with mantle heater and condenser (Fig. 4).

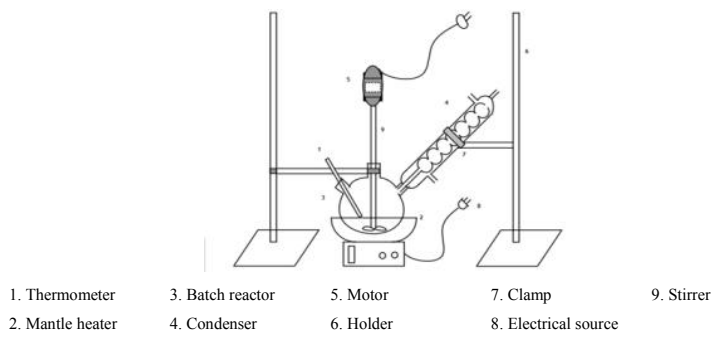

Fig. 4. Experimental set up

The experiments were run in two steps. The first step was brazilein extraction from the shaved sappanwood which was blended first with the solvent using high speed liquid blender. Extraction was run at its optimum conditions [7], which were previously obtained with aquadest as solvent, using the concentration of solid in the solvent of $0.002 \mathrm{~g} / \mathrm{L}$, with the mixing speed of 300 $\mathrm{rpm}$, and 70 minutes of extraction at constant temperature of $100^{\circ} \mathrm{C}$. The second step was the improvement of the extract, in term of its color spectrum and intensity by chemical modification using additives. Two routes were tested for the chemical modification, which were acid-base reaction and cation reaction.

Chemical modification using acid-base addition was conducted to check the color characteristics under different $\mathrm{pH}$ values [8]. For acidic $\mathrm{pH}, 15 \mathrm{~mL}$ of citric acid or acetic acid (both at $0.1 \mathrm{M}$ concentration) was added into $100 \mathrm{~mL}$ of original extract, while for basic $\mathrm{pH}, 15 \mathrm{~mL}$ of sodium hydroxide or calcium hydroxide solution (both at $0.1 \mathrm{M}$ concentration) was added into $100 \mathrm{~mL}$ of original extract. Other type of additive tested in this study was cation addition. Solutions of $\mathrm{Cu}$-Asetat, $\mathrm{MgSO}_{4}, \mathrm{Al}_{2}\left(\mathrm{SO}_{4}\right)_{3}$ and $\mathrm{FeSO}_{4}$ were used as the provider of cations.

After the process with each method, the absorbance of the modified extract was quantitatively measured using UV-Vis spectrophotometer. Spectrophotometer was chosen over chromometer because it offered wider and more flexible measurement range coverage of spectra. The data were recorded as the absorbance measured at the optimum wavelength for each color spectrum, i.e. the wavelength which gave the minimum transmittance for a particular sample. Scanning of optimum wavelength was conducted by measuring the absorbance of each sample at various wavelengths.

\section{Results and discussions}

\subsection{Acid-base modifications}

\subsubsection{Addition of acids}

According to the Classic RAL System, the color of the original extract was categorized as traffic red. Both acid addition, i.e. acetic acid and citric acid, shifted the color category into dahlia yellow. The visual comparison of the colors is presented in Fig. 5. For more objective comparison, Fig. 6 presents the absorbance data of the original and modified extracts.

The absorbance data in Fig. 6 reveals that all extracts exhibits the highest absorbance at the same wavelength, i.e. $440 \mathrm{~nm}$ (indicated by vertical line on Fig. 6). This fact translates into more objective interpretation than the visual observation, that acid addition does not change the spectrum of the color, although visually the colors look different. The change caused by acid addition was actually on the intensity of the colors. Fig. 6 shows that the addition of acids significantly lowered the color intensity of the original extract. 


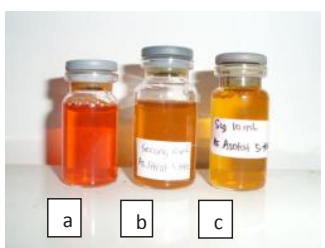

Fig. 5. Visual comparison of original extract (a) with the citric acid added extract (b) and acetic acid added extract (c)

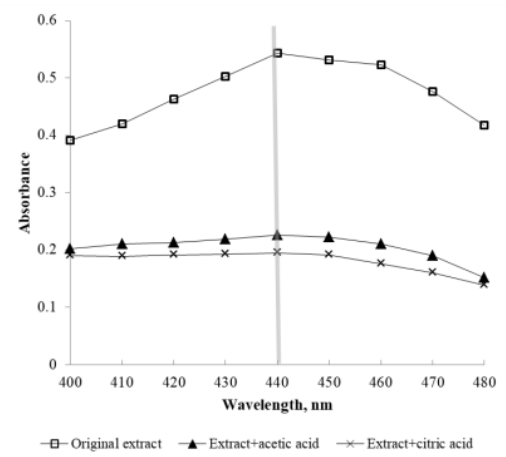

Fig. 6. The change of color intensity by acid addition into original extract of sappanwood based on UV-Vis absorbance data

Both Fig. 5 and Fig. 6 show that different acids (citric acid and acetic acid) did not cause different spectrum or different intensity. This confirms that the change of intensity by acid addition was caused by the $\mathrm{H}+$ protons so that different acyl (RCO-) group arrangement of the acids did not matter. The effect of $\mathrm{H}^{+}$ proton concentration was then tested by the addition of different amount of citric acids, which gave the variations of color intensity presented in Fig. 7 (for citric acid addition) and Fig. 8 (for acetic acid addition). With the extra $\mathrm{H}^{+}$protons available in the solution from acid partial dissociation, the hydroxyl groups of the brazilein became protonated [9]. As a result of that, the initially localized electrons in the $\pi$-conjugated orbitals of the double bonds in brazilein molecule became somehow delocalized [2]. Hence, slightly different shade of color was observed.

Slight difference in $\mathrm{H}^{+}$proton concentration was created by the addition of different amount of acid solutions, i.e. $0.06 \mathrm{~mL}, 0.15 \mathrm{~mL}$, and $0.3 \mathrm{~mL}$ in $10 \mathrm{~mL}$ of original extract. Fig. 7 and Fig. 8 show that color intensity was not very sensitive to $\mathrm{H}^{+}$proton concentration as the mechanism of color changes was only due to electron delocalization.

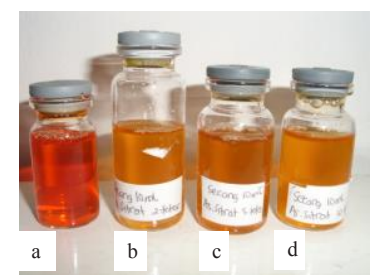

Fig. 7. Visual comparison of original extract (a) with citric acid added extract: $0.06 \mathrm{~mL}$ (b), $0.15 \mathrm{~mL}$ (c), and $0.30 \mathrm{~mL}$ (d) of citric acid into $10 \mathrm{~mL}$ of original extracts

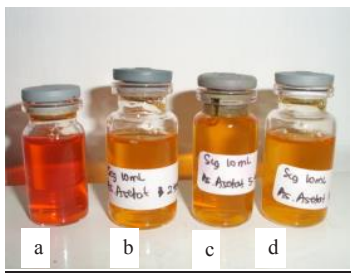

Fig. 8. Visual comparison of original extract (a) with acetic acid added extract: $0.06 \mathrm{~mL}$ (b), $0.15 \mathrm{~mL}$ (c), and $0.30 \mathrm{~mL}$ (d) of acetic acid into $10 \mathrm{~mL}$ of original extracts

\subsubsection{Base addition}

The addition of bases into the original extract of sappanwood gave totally different results from the acid additions. Both bases tested in this experiment, i.e. $\mathrm{NaOH}$ dan $\mathrm{Ca}(\mathrm{OH})_{2}$, shifted the originally traffic red of the original extract into ruby red. Fig. 9 presents a visual comparison between the original extract and the baseadded extract, which used $\mathrm{NaOH}$ as the base. The addition of $\mathrm{Ca}(\mathrm{OH})_{2}$ led to the same color change, however it was not suggested as it turned out that $\mathrm{Ca}(\mathrm{OH})_{2}$ solution induced precipitation of the extract. The absorbance analysis was then only conducted on $\mathrm{NaOH}$ added extract and the result is presented in Fig. 10

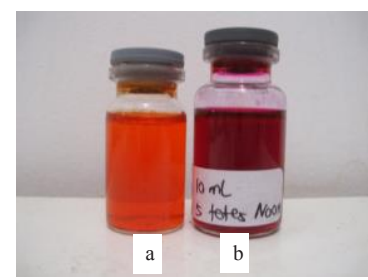

Fig. 9. Visual comparison of original extract (a) with $\mathrm{NaOH}$ added extract (b) 


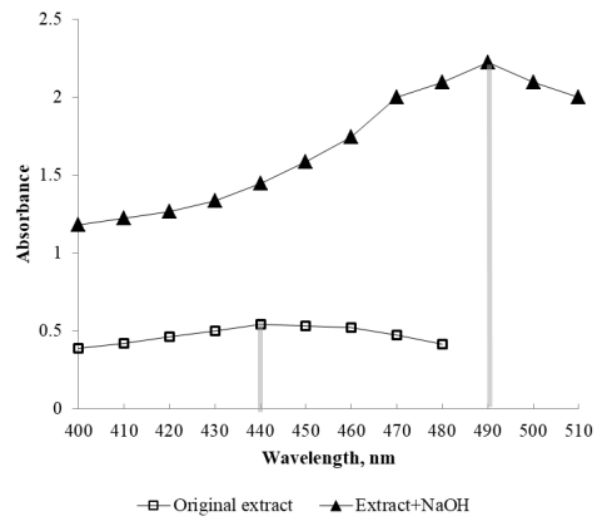

Fig. 10. The change of color intensity and color spectrum by base addition into original extract of sappanwood based on UV-Vis absorbance data

Fig. 10 exhibits that the addition of $\mathrm{NaOH}$ solution induced not only the change of color intensity but also shifted the wavelength which gave the maximum absorbance, from $440 \mathrm{~nm}$ for the original extract into $490 \mathrm{~nm}$. It means that the color resulted from base addition was of quite different spectrum from the original extract. Such change could only be caused by the change of the the electron distribution caused by the addition of $\mathrm{NaOH}$, which shifted the $\mathrm{pH}$ into basic environment.

The hydroxyl ions from the base dissociation created deprotonation of the hydroxyl groups in the brazilein molecules. Consequently, there were spots with high density electrons in some parts of the molecules. This variations in electron localization created different shades of colors. Further tests were conducted to strengthen this speculation, i.e. the addition of different concentrations of $\mathrm{NaOH}$ solution (Fig. 11). In Fig. 11, referring to the RAL system of color standardization, the addition of $0.06 \mathrm{~mL}$ of $\mathrm{NaOH}$ resulted in signal red, 0.15 $\mathrm{mL}$ addition of $\mathrm{NaOH}$ solution gave ruby red, and 0.3 $\mathrm{mL}$ of $\mathrm{NaOH}$ addition made pearl ruby red. In contrast to the protonation of hydroxyl groups in the previous section which did not change the color shade, the deprotonation occurred in the brazilein molecules more significantly affected the color spectrum of the extract.

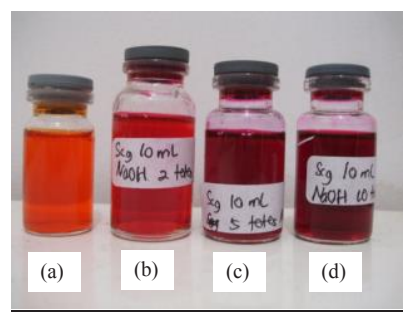

Fig. 11. Visual comparison of original extract (a) with $\mathrm{NaOH}$ added extract: $0.06 \mathrm{~mL}$ (b), $0.15 \mathrm{~mL}$ (c), and 0.30 $\mathrm{mL}(\mathrm{d})$ of $\mathrm{NaOH}$ solution into $10 \mathrm{~mL}$ of original extracts

\subsection{Effect of cations from mordant salts}

Four transition metal cationic solutions of mordant salts were tested, which were $\mathrm{MgSO}_{4},\left(\mathrm{CH}_{3} \mathrm{COO}\right)_{2} \mathrm{Cu}, \mathrm{FeSO}_{4}$, and $\mathrm{Al}_{2}\left(\mathrm{SO}_{4}\right)_{3}$. As being displayed in Fig. 12, the addition of $\mathrm{MgSO}_{4}$ solution or $\mathrm{Al}_{2}\left(\mathrm{SO}_{4}\right)_{3}$ solution into the original extract did not change the color spectrum as it was still traffic red. Other color, claret violet (which gave optimum absorbance at $510 \mathrm{~nm}$ of wavelength), was resulted when $\left(\mathrm{CH}_{3} \mathrm{COO}\right)_{2} \mathrm{Cu}$ solution was added with dilution. Addition of $\mathrm{FeSO}_{4}$ solution (also with dilution) gave red lilac color (optimally absorbing light at $500 \mathrm{~nm}$ of wavelength). The various spectra created by cation addition from the solutions studied in this research were presented in Fig. 13.

The new spectra found by the addition of mordant salts were broader than those obtained in acid-base equilibria explained in the previous section. Transitional metals were known for their ability of chelating, i.e. complex formation with organic compounds. The $\mathrm{d}$ and $\mathrm{f}$ orbitals of the transition metal were only partially filled so that it was easy to form bonding with any nucleophiles, although the bonding could be weak or strong, depending upon the period of the metal [2]. It can be noticed in Fig. 12 that most intense colors were caused by $\mathrm{Fe}^{2+}$ and $\mathrm{Cu}^{2+}$ cations, while $\mathrm{Al}^{3+}$ and $\mathrm{Mg}^{2+}$ did not induce such strong colors (similar to the color with the presence of $\mathrm{Na}^{+}$described in the previous section). These results were in good accordance to the theoretical reasons of the chelating strength of different groups of transitional metals [5]. Group 1 cation $\left(\mathrm{Mg}^{2+}\right)$ and group 2 cation $\left(\mathrm{Al}^{3+}\right)$ did not have strong tendency to form complexes with the brazilein so that they failed to concentrate the electrons to create deeper colors. On the other hand, group 3 cations $\left(\mathrm{Fe}^{2+}\right.$ and $\left.\mathrm{Cu}^{2+}\right)$ were known for their ability to form coordinated complexes with brazilein. Up to 6 molecules of brazilein could be bond around one cation and hence it induced very deep color.

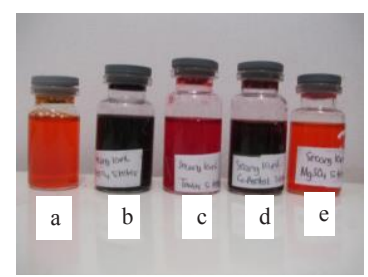

Fig. 12. Visual comparison of original extract (a) and with addition of $\mathrm{FeSO}_{4}(\mathrm{~b}), \mathrm{Al}_{2}\left(\mathrm{SO}_{4}\right)_{3}$ (c), $\left(\mathrm{CH}_{3} \mathrm{COO}\right)_{2} \mathrm{Cu}$ (d), and $\mathrm{MgSO}_{4}(\mathrm{e})$ 


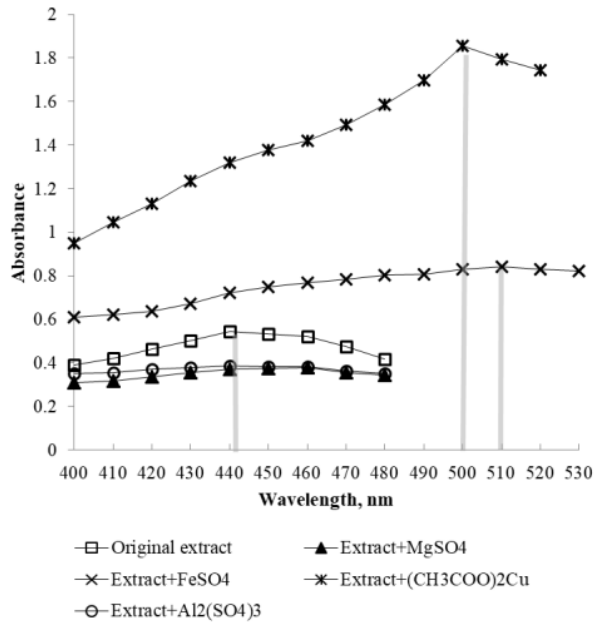

Fig. 13. The change of color intensity and color spectrum by cation addition into original extract of sappanwood based on UV-Vis absorbance data

\section{Conclusions}

The phenomenological study on the efforts of intensifying the color and expanding the spectra of sappanwood extract raised important understandings as the following:

a. Acid addition changed color intensity but did not affect the spectrum. The intensity variations might be dominantly influenced by the $\mathrm{H}^{+}$proton from the dissociated acids, which induced protonation of the hydroxyl groups in the brazilein structure. The protonation created delocalization of electrons so that they were not concentrated on the double bonds and hence the colors of the extract turned lighter. The alkyl group of the organic acids tested in this study had no influence on both color intensity and spectrum.

b. Base addition not only changed the intensity of the color but also expanded the spectra. In this case, the hydroxyl ion from the base caused deprotonation of the hydroxyl groups in the brazilein structure. Consequently, the electrons became localized around the deprotonated hydroxyl groups and induced deeper colors.

c. Different cations created different shades of colors. The sources of cations were usually mordant salts, which were salts from transitional metal. Metals from group 1 and 2 (such as $\mathrm{Mg}^{2+}$ and $\mathrm{Al}^{3+}$ ) might be useful as mordant (to fix the color onto the fiber), however, they did not have the chelating strength to form complexes with the brazilein. They could not concentrate dye molecules to create deeper colors. On the other hand, metals from group $3\left(\mathrm{Fe}^{2+}\right.$ and $\left.\mathrm{Cu}^{2+}\right)$ could form strong coordinated complexes with the brazilein. Therefore, $\mathrm{Fe}^{2+}$ and $\mathrm{Cu}^{2+}$ were not only functioning as the mordant but also could create deeper colors as well.

\section{References}

1. N. P. Nirmal, M. S. Rajput, R. G. S. V. Prasad, and M. Ahmad, Asian Pac. J. Trop. Med., 8(6), 421-430, (2015).

2. G. Richhariya, A. Kumar, P. Tekasakul, and B. Gupta, Renew. Sustain. Energy Rev., 69, 705718, (2017).

3. R. Rondão, J. S. Seixas De Melo, J. Pina, M. J. Melo, T. Vitorino, and A. J. Parola, J. Phys. Chem. A, 117(41), 10650-10660, (2013).

4. A. Manhita, V. Santos, H. Vargas, A. Candeias, T. Ferreira, and C. B. Dias, J. Cult. Herit., 14(6), 471-479, (2013).

5. A. Moiz, M. Aleem Ahmed, N. Kausar, K. Ahmed, and M. Sohail, J. Saudi Chem. Soc., 14(1), 69-76, (2010).

6. S. Masood, M. A. Randhawa, M. S. Butt, and M. Asghar, J. Food Process. Preserv., 40(1), 313, (2016).

7. M. T. Wahyuningrum, Penentuan Kondisi Operasi Optimum Ekstraksi Brazilin dari Kayu Secang, No Title," Yogyakarta, (2003).

8. H. . Prasasti, Peningkatan intensitas dan perluasan spektrum warna dari ekstrak kayu secang (Caesalpinia sappan L), Yogyakarta, 2013.

9. G. Solomons, C. Fryhle, and S. Snyder, "Org. Chem., 1255, (2014). 